\title{
On the Andean genus Leschenius (Coleoptera: Curculionidae: Entiminae): Updated phylogeny, with a new species from Ecuador, discovery of males, and larval description of the potato weevil Leschenius vulcanorum
}

\author{
Maria Guadalupe del Rio ${ }^{\text {Corresp., Equal first author, } 1 \text {, Adriana E Marvaldi }}{ }^{\text {Corresp. Equal first author, } 1}$ \\ 1 División Entomología, Museo de La Plata, Universidad Nacional de La Plata, CONICET, La Plata, Buenos Aires, Argentina \\ Corresponding Authors: Maria Guadalupe del Rio, Adriana E Marvaldi \\ Email address: gdelrio@fcnym.unlp.edu.ar, marvaldi@fcnym.unlp.edu.ar
}

The weevil genus Leschenius del Río (Curculionidae: Entiminae: Naupactini) is distributed in the northern Andes, in Colombia and Ecuador. Among its species, L. vulcanorum stands out as an important pest of potatoes in its parthenogenetic form, known as "tiroteador de la papa". In this study, the adult male and the larval stage (first and mature larvae) of $L$. vulcanorun are described and illustrated for the first time. A description of the male of Leschenius bifurcatus is also provided. A new bisexual species was discovered, Leschenius ventrilingulatus sp. nov., and is described from Ecuador. An updated phylogenetic analysis was performed, including the new species, with results indicating a sister group relationship between $L$. ventrilingulatus and $L$. vulcanorum. They can be distinguished because the former is usually of smaller size and is covered by denser and thicker setae, it has shorter antennae, a subcylindrical shape of the pronotum, shorter elytra (about 1.5x longer than wide at base), the female has ventrite 4 with a posterior rounded projection, and posterior margin of ventrite 5 subacute, not excavated. This paper also includes lectotype designations, a revised key to all known species of Leschenius, habitus photos of males and females, illustrations of genitalia, and a distribution map. 


\section{On the Andean genus Leschenius (Coleoptera:}

2 Curculionidae: Entiminae): Updated phylogeny, with a

3 new species from Ecuador, discovery of males, and

4 larval description of the potato weevil Leschenius

5 vulcanorum

6

7 María Guadalupe del Río, Adriana Elena Marvaldi

8

9 División Entomología, Museo de La Plata, FCNyM, UNLP, CONICET, La Plata, Buenos Aires, 10 Argentina.

12 Corresponding Authors:

13 María G. del Río

14 Paseo del Bosque s/n, La Plata, 1900, Buenos Aires, Argentina.

15 Email address: gdelrio@fcnym.unlp.edu.ar

Adriana Marvaldi

Paseo del Bosque s/n, La Plata, 1900, Buenos Aires, Argentina.

Email address: marvaldi@fcnym.unlp.edu.ar 


\section{Abstract}

36 The weevil genus Leschenius del Río (Curculionidae: Entiminae: Naupactini) is distributed in the northern Andes, in Colombia and Ecuador. Among its species, L. vulcanorum stands out as an important pest of potatoes in its parthenogenetic form, known as "tiroteador de la papa". In this study, the adult male and the larval stage (first and mature larvae) of L. vulcanorun are described and illustrated for the first time. A description of the male of Leschenius bifurcatus is also provided. A new bisexual species was discovered, Leschenius ventrilingulatus sp. nov., and is described from Ecuador. An updated phylogenetic analysis was performed, including the new species, with results indicating a sister group relationship between $L$. ventrilingulatus and $L$. vulcanorum. They can be distinguished because the former is usually of smaller size and is covered by denser and thicker setae, it has shorter antennae, a subcylindrical shape of the 46 pronotum, shorter elytra (about 1.5x longer than wide at base), the female has ventrite 4 with a posterior rounded projection, and posterior margin of ventrite 5 subacute, not excavated. This paper also includes lectotype designations, a revised key to all known species of Leschenius, habitus photos of males and females, illustrations of genitalia, and a distribution map.

\section{Introduction}

The weevils of the South American genus Leschenius del Río (Curculionidae, Entiminae, Naupactini) range in the highlands of Colombia and Ecuador, at approximately 1800 to 5000 m.a.s.1. (del Río, Marvaldi \& Lanteri, 2012). According to the phylogeny of the Naupactini tribe by Lanteri \& del Río (2017), the genus Leschenius belongs to the so-called "Andean group", a clade of genera distributed in the Andes: (Asymmathetes Wibmer \& O'Brien (Amphideritus Schoenherr (Leschenius (Amitrus Schoenherr (Obrieniolus del Río (Melanocyphus Jekel, Trichocyphus Heller)))))), supported by the pro-femora about as wide as meta-femora and by some features of the vestiture like the scarcity of scales and the elytral setae being either erect and long or absent. The "Andean group" belongs to a larger clade, defined by the reduction of the elytral humeri and metathoracic wings, that includes most genera often related to Pantomorus Schoenherr sensu lato, like Atrichonotus Buchanan, Aramigus Horn, Phacepholis Horn, Parapantomorus Emden (Lanteri \& del Río 2017).

Leschenius is recognized by the black, denuded, and shiny integument, the welldeveloped denuded ridge at the apex of the rostrum, bordering the mandibles (pre-epistome), the 
67 pronotal base "V" shaped, the elytral base curved backward, the reduction of the metathoracic

68 wings, and by the procoxae separated and situated much closer to the anterior than to the

69

70

71

72

73

74

75

76

77

78

79

80

81

82

83

84

85

86

87

88

89

90

91

92

93

94

95

96

97

98

posterior margin of the prosternum. Mixed in the series of L. vulcanorum (Kirsch), we found

some specimens which differ in some diagnostic characters such as the length of the elytra, the

density of the vestiture, and the shape of the female ventrite 4. After close examination, we

concluded that these specimens correspond to a new bisexual species, L. ventrilingulatus del Río

\& Marvaldi sp. nov., close to L. vulcanorum. We also found male specimens, previously

unnoticed, as belonging to L. vulcanorum. Finally, and despite its great economic importance as

a potato pest, we realized there was not a detailed larval description for this species, or any

representative of Leschenius.

The purpose of this contribution was to provide a systematic update of the

genus Leschenius, including descriptions of a new species, the larva of L. vulcanorum, the males of L. vulcanorum and L. bifurcatus del Río, Marvaldi \& Lanteri, along with lectotype designations, updated phylogenetic analysis and a revised key to all known species of the genus.

\section{Materials \& Methods}

The study was based upon the examination of adult specimens borrowed from the following institutions: Charles O'Brien collection, now housed at Arizona State University (ASUCOB, Tempe, USA), The Natural History Museum (BMNH, London, UK), Museo de La Plata (MLPC, La Plata, Argentina), Muséum National d'Histoire Naturelle, (MNHN, Paris, France), Museum für Tierkunde, (MTD, Dresden, Germany), Museum für Naturkunde (ZMB, Berlin, Germany). Immature stages. The slide-mounted larval specimens are deposited at the MLPC, labelled with the data of this article. Techniques for dissection of larvae, terminology and abbreviations herein applied corresponds to Marvaldi (1998).

Dissections of genitalia were made according to standard entomological techniques, and characters were drawn using a camera lucida adapted to a stereoscopic microscope (Nikon SMZ800). All measurements were taken with an ocular micrometer attached to the same microscope, and their abbreviations used in the description are as follows: L, maximum length; LA, length of antennae; LB, length of body; LE, length of elytra; LP, length of pronotum; W, maximum width; WRa, width of rostrum measured across apex (excluding scrobes); WRb, width

Peer] reviewing PDF | (2021:11:67992:2:0:NEW 12 Jan 2022) 
99 of rostrum at anterior margins of eyes. The terminology used for the morphological structures

100 follows Marvaldi et al. (2014), Lanteri \& del Río (2017) and the glossary of weevil characters by

101 Lyal (2021). The terminology used for the sculpture follows that of Harris (1979).

102 The electronic version of this article in Portable Document Format (PDF) will represent a

103 published work according to the International Commission on Zoological Nomenclature (ICZN),

104 and hence the new names contained in the electronic version are effectively published under that

105 Code from the electronic edition alone. This published work and the nomenclatural acts it

106 contains have been registered in ZooBank, the online registration system for the ICZN. The

107 ZooBank LSIDs (Life Science Identifiers) can be resolved and the associated information viewed

108 through any standard web browser by appending the LSID to the prefix http://zoobank.org/. The

109 LSID for this publication is: urn:1sid:zoobank.org:pub:348600A7-0721-4BC9-A3FD-

110 CB5CBDC55954. The online version of this work is archived and available from the following

111 digital repositories: PeerJ, PubMed Central SCIE and CLOCKSS.

112

113 Phylogenetic analysis

114 For the phylogenetic analysis of Leschenius, the list of morphological characters and the data

115 matrix by del Río, Marvaldi \& Lanteri (2012) were modified to include the new species as a

116 terminal taxon as well as new information about the males of Leschenius vulcanorum and $L$.

117 bifurcatus.

118 For the inclusion of the new species in the present analysis, four characters from the list by del

119 del Río, Marvaldi \& Lanteri (2012) were redefined (chars. 5, 41, 47, and 48), and a new one for

120 the male genitalia was added (Table 1). The new list consisted of 50 morphological characters of

121 the adults, including 36 from the external morphology and 14 from the female (9) and male

122 terminalia (5). The data matrix herein analyzed includes 12 terminal taxa, corresponding to seven

123 species of Leschenius plus five outgroup taxa (Table 2) closely related to Leschenius according

124 to Lanteri \& del Río (2017). All characters were treated as non-additive and analyzed under

125 equal weights.

126 A cladistic analysis was conducted with TNT v1.5 (Goloboff \& Catalano, 2016), using

127 the "traditional search" algorithm, with 100 random addition sequences, Tree Bisection and

128 Reconnection (TBR) branch swapping, holding 10 trees during each replication. The most

129 parsimonious tree was rooted with Melanocyphus lugubris. Clade stability was evaluated with

PeerJ reviewing PDF | (2021:11:67992:2:0:NEW 12 Jan 2022) 
1301000 replication Bootstrap (BT) (Felsenstein, 1985), support values over $50 \%$ were indicated 131 below branches. The total length (L), the consistency index (CI) (Kluge \& Farris, 1969), and the 132 retention index (RI) (Farris, 1989) of the most parsimonious trees (MP tree) were calculated 133 excluding the uninformative characters. The character changes were mapped on the tree using 134 fast (ACCTRAN) optimization with WINCLADA1.00.08 (Nixon, 2002).

135

136

137

138

139

140

141

142

143

144

145

146

147

148

149

150

151

152

153

154

155

156

157

158

159

160

161

\section{Results}

Cladistics. The analysis yielded one most parsimonious tree ( $\mathrm{L}=155$ steps, $\mathrm{CI}=0.56, \mathrm{RI}=$ 0.53) (Fig. 1). In the cladogram Asymmathetes pascoei is the sister group of Leschenius, relationship that is supported by several synapomorphies (at least 10 exclusive and one homoplastic character changes, shown in Fig. 1). Leschenius is monophyletic and includes the new species, L. ventrilingulatus, sharing the synapomorphies of the genus: the well-developed pre-epistome (character 10.1); the ' $\mathrm{V}$ '-shaped pronotal base (character 17.2); the slightly prominent to absent elytral humeri (character 23.1); and the procoxae almost contiguous with anterior margin of prosternum (character 29.0). Leschenius is also supported by five homoplastic characters states: antennal scape slightly exceeding posterior margin of eyes (character 12.2, with reversal to 12.1 in L. nigrans-L.manueli clade); funicle segments 2 and 1 subequal (character 13.2, with reversal to 13.1 in L. vulcanorum and L. rugicollis); elytral base straight to slightly curved backwards (character 21.1) with evolutionary transition to 21.2 in L. nigrans-L.manueli clade (apomorphic with a reversal to 21.1 in L. nigrans). The latter is an important character for Leschenius because all the other genera of the "Andean group" have the elytral base bisinuate (21.0).

The genus Leschenius has two main clades, named A and B in Fig. 1. Clade A is well supported and includes the new species, $L$. ventrilingulatus as sister of $L$. vulcanorum, a relationship supported by the very short rostrum (character 5.2), the relatively wide pronotum (character 14.1), the short cornu of spermatheca (character 44.0); the penis with its apex tapering into a long acute projection (character 47.0), dorsally slightly recurved (character 49.1), with a long flagelum like sclerotization in the endophallus (character 48.2). Clade B includes the remaining five species of the genus, supported by the rostral sulcus exceeding posterior margin of eyes (character 7.1), corbel of metatibial apex narrow, setose or denuded (character 31.2); penis apodemes half as long as penis body (character 45.1), and by some homoplastic characters

Peer) reviewing PDF | (2021:11:67992:2:0:NEW 12 Jan 2022) 
162 such as medium sized body (character 0.1 ), sides of rostrum slightly convergent towards apex 163 (character 6.0), and presence of apical projection of elytra (character 24.1). In clade B, $L$.

164 bifurcatus is the sister of the remaining species, which form a clade defined by the elytral base 165 strongly curved backwards (character 21.2) and by the homoplastic characters: antennal scape 166 reaching posterior margin of eye (character 12.1), pronotum slightly conical (character 15.1) 167 with lateral angles projected in males (character 18.1), and humeral angle of males anteriorly 168 projected (character 22.1). They are grouped in two sister subclades, one including $L$.

169 nigrans and L. silviae, defined by one synapomorphy, the obtuse angle between the longitudinal 170 axis of penis and its apodemes (character 46.1), and four homoplastic character states: funicle 171 segment 2 more than 1.5 times longer than segment 1 (character 13.0), maximum width of elytra 172 at anterior third (character 20.2), apical comb of metatibiae longer than dorsal comb (character 173 32.0), and blunt posterior margin of ventrite 5 in males (character 35.3). The other subclade 174 includes L. rugicollis and L. manueli and is supported by two synapomorphies, strongly convex 175 eyes (character 11.0), and apex of median lobe evenly rounded (character 47.3), plus three 176 homoplastic character states, the rostrum and forehead coarsely strigose (character 3.3), 177 pronotum foveolate-granulose (character 4.2), and penis apodemes slightly shorter than penis 178 body (character 45.0).

179

180

181

Taxonomy

81 Leschenius del Río 2012

182 Leschenius del Río in del Río, Marvaldi \& Lanteri 2012: 55.

183

184

Most characters of the following larval description, based on specimens of L. vulcanorum, may 185 apply to the genus Leschenius. Terminology as in Marvaldi (1998).

186

187

Description of larvae. Mature larva. Body robust, widest at thorax and first abdominal segments. Cuticle asperities present on ventral areas and absent on lateral and dorsal areas. Head 189 (Fig. 2A). Deeply retracted into thorax, longer than wide; posterior margin ogival; posterior half unpigmented, with softer integument and without setae; all setae shifted anteriorly, placed on anterior third. Epicranial line more than $0.5 \mathrm{x}$ the length of head capsule. Frontal lines and endocarina absent. Hypopharyngeal bracon with paramedian maculae. Postoccipital condyles 
193 obtuse, hyaline. Setae (Fig. 2A): $f_{s} 4,5$, des5, and les2 long, subequal situated on anterior cephalic 194 fifth; des 1, des3 shorter but well developed; fs 1,2,3, des4, pes 1-4 minute; les 1 reduced; vcs 1 195 longer than $v c s 2$, both short. Stemmata absent. Antenna (Fig. 2B) with sensorium about $2.5 \mathrm{x}$

196

197

198

199

200

201

202

203

204

205

206

207

208

209

210

211

212

213

214

215

216

217

218

219

220

221

222

223 wider than long, truncate at apex. Labrum (Fig. 2C) with $\operatorname{lm} s 1,2,3$, subequal, $\operatorname{lm} s 1$ slightly less widely separated than $l m s 2$. Epipharynx (Fig. 2D) with mes 1 less separated than mes2; epipharyngeal sensilla as single units (not as sensillum clusters), one pair between mes 1 and mes 2 but closer to mes 2 , and another pair close to bases of labral rods; labral rods (Fig. 2D) ax shaped, bifurcate, with one arm reaching mes 1 and the other mes2. Mandibles (Fig. 2E) with $m d s 1$ slightly longer than $m d s 2$, both transversely placed within the scrobe; $m d s 2$ exterior and slightly basal to $m d s 1$. Maxillae (Fig. 2F-G) with spinules on dorsal surface of external margin of stipes and below mala and palpus; maxillary mala with a row of eight $d m s$ and with four vms. Labium (Fig. 2F) with premental sclerite well sclerotized, with posterior extension truncate and expanded at apex, anterior extension slender. Thorax (Fig. 3A). Spiracle (Fig. 3E) ellipsoidal, without airtubes. Pronotum (Fig. 3A) with nine setae. Meso- and metathorax with pds3 distinctly longer than others; alar area with two as. Pedal areas of thoracic segments (Figs. 3A-B) each with nine setae: seta $z$ conspicuous; setae $x$ and $y$ subequal; $u$ smaller than $v ; v$ smaller than $w$; seta $v^{\prime}$ present and rather conspicuous; small $x$ ' distinct; a pair of additional anterosternal microsetae occasionally present in front of each pedal area. Abdomen (Figs. 3C-D, F): Spiracles (Fig. 3E) elliptical, 2x smaller than thoracic one, without airtubes. Segments AI-VII (Figs. 3A, C) with five $p d s, p d s 3$ and $p d s 5$ the longest; spiracular area with only ss 2 distinct and progressively placed closer to postdorsum, ss 1 vestigial or absent. AVIII with four $p d s$, lacking the homologous $p d s 2$ of preceding segments; ss indistinct. Abdominal apex (Fig. 3D) modified, with transverse posterior sclerotized ridges on dorsum, pleura and sternum of AIX; AIX with four $d s$ including a seta $d s^{\prime}$, placed lateral to $d s l$; laterally with two $l s$ strongly unequal, the longest on sclerotized ridge; AX terminal, four-lobed, each lateral anal lobe with three minute setae, the outermost larger.

19 First instar larva (Figs. 2H-J, 3E). Head (Figs. 2H-I) only slightly retracted into thorax, slightly longer than wide; major cephalic setae placed on anterior half, des 2 and les 1 less reduced than in older larvae; des 1 minute (smaller than in mature larvae). Frontal lines weakly distinct. Anterior and posterior stemmata distinct, as dark pigmented spots. Antennal sensorium prominent and projected outwards. Mandibles (Fig. 2J) with $m d s 1,2$ strongly unequal, $m d s 1$ 
224 about $5 \mathrm{x}$ longer than $m d s 2$. Thorax. Spiracle (Fig. 3F) bicameral with annulated airtubes; pedal 225 area with setae $z$, and $v^{\prime}$ relatively small, seta $w$ relatively very long and spatulate or blunt at 226 apex. Abdomen. Spiracles (Fig. 3F) bicameral, with airtubes having a smaller number of rings 227 than thoracic one; abdominal apex not distinctly sclerotized.

228

229

230

231

232

233

234

235

236

237

238

239

240

241

242

243

244

245

246

247

248

249

250

251

252

253

254

Remarks. The characters mentioned above for the first larva, newly hatched, are exclusive of the first instar (see also Marvaldi \& Loiácono, 1994). Additional differences between early and older instar larvae involve relative dimension of structures, like the antennal sensorium, which are relatively much larger in the first instar; the pigmentation and level of sclerotization of body areas tend to increase in successive instars; there are larger differences in length between setae of different body areas in early instars.

Comparative notes. The larval characters given herein for the genus Leschenius are in full agreement with those defining the tribe Naupactini (Marvaldi \& Loiácono, 1994) or Naupactus and allied genera (Marvaldi, 1998). Two apparently distinct features of the mature larva studied of L. vulcanorum are the head capsule with des 1 well developed (in known mature larvae of other Naupactini des 1 is minute or very small); also, setae $x$ and $y$ of pedal areas of thoracic segments are subequal (in other Naupactini as Naupactus, seta $x$ is distinctly smaller than $y$ ). Larval characters deemed as diagnostic for the species are given below.

Notes on type material. Four paratypes of the species of Leschenius described in del Río, Marvaldi \& Lanteri (2012) were finally deposited in the MLPC instead of the collection mentioned in the original publication: one paratype of $L$. bifurcatus del Río, Marvaldi \& Lanteri, with labels 'ECUADOR, PICHINCHA, POMASQUI, RUNICUCHO, 2400 m, 6-XII-1993, K. Volbracht'; two paratypes of L. manueli del Río, Marvaldi \& Lanteri, with labels 'ECUADOR, AZUAY, VIA CUENCA LOJA, 5 km DE ONA, 13-I-1997, A. Paucar'; and one paratype of $L$. silviae del Río, Marvaldi \& Lanteri, with label 'Cuenca Jesta'.

\section{Leschenius vulcanorum (Kirsch, 1889)}

(Figs. 2, 3, 4, 5A, 6G, K, 7)

Canephorus vulcanorum Kirsch 1889: 17; Strand 1943: 96 (Canephorulana); 
255 Kuschel 1955: 277 (Amitrus); Kuschel in Wibmer \& O'Brien 1986: 53 (Asymmathetes) (Fig. 256 4A).

257 Amphideritus brevis Oliff 1891: 68; DallaTorre, Emden \& Emden 1936: 14 (Macrostylus);

258 Kuschel 1955: 277 (Amitrus) (syn. of A. vulcanorum); Kuschel in Wibmer \& O’Brien 1986: 53

259 (Asymmathetes); del Río, Marvaldi \& Lanteri 2012: 60 (Leschenius) (Fig. 4B).

260 Amphideritus pigmaeus Oliff 1891: 68; Dalla Torre, Emden \& Emden 1936: 14 (Macrostylus);

261 Kuschel 1955: 277 (Amitrus) (syn. of A. vulcanorum); Kuschel in Wibmer \& O’Brien 1986: 53

262 (Asymmathetes) (Fig. 4C).

263 Caulostrophus aequatorialis Kirsch 1889: 13; Dalla Torre, Emden \& Emden 1939: 319

264 (Macrostylus [Amphideritus]); Kuschel in Wibmer \& O’Brien 1986: 53 (Asymmathetes) (Fig.

265 4D), syn. n.

266

267 Diagnosis and description of female in del Río, Marvaldi \& Lanteri (2012).

268

269

Description of male (Fig. 5A). Smaller than female (4.0-6.3 mm; females 5.3-8.7 mm); rostrum 270 shorter (L/Wa: 0.76-0.84); less convergent towards apex (Wb/Wa, 1.15-1.30); antennal club 271 more elongate (L/W, 2.5-2.8); pronotum (W/L: 1.25-1.35), wider than the elytra and longer than 272 in females, with sides more arcuate; elytra slightly shorter (L/W, 1.32-1.40) with apex not 273 divided, more rounded; metatibiae with larger mucro than in females; posterior margin of 274 ventrite 5 blunt. Genitalia (Figs $6 \mathrm{G}, \mathrm{K}$ ). Median lobe slightly curved in lateral view, tapering 275 towards apex, with subacute, dorsad slightly recurved hook-like apex; penis as long as abdomen; 276 apodemes slightly shorter than median lobe $(0.7 \mathrm{x})$; endophallus armed with minute spicules and 277 with a slightly sclerotized flagellum.

278

279 Larval stage. One mature larva and four submature larvae, as well as associated adults of $L$.

280 vulcanorum, were collected from the following locality: Colombia, Municipio

281 de Sibaté, vereda el Romeral, 4²6'3'’N, 74¹4'8'” O (3100 masl), J.E.C. Gomez leg., 2009.

282 Additionally, 10 first instar larvae were obtained from eggs deposited by some of the collected

283 adults kept in captivity. After comparison with larvae known for other species in tribe Naupactini 284 (Marvaldi \& Loaiácono, 1994; Marvaldi, 1998) the following combination of characters can be 285 suggested as diagnostic for the species L. vulcanorum. 
286 Mature larva (Figs. 2-G, 3A-E). Maximum head width $2.2 \mathrm{~mm}$. Setae fine, brown. Head 287 yellowish, intense yellow on anterior margin of frons, about $1.3 \mathrm{x}$ longer than wide. Cephalic 288 setae (Fig. 2A): des 1 well developed (although shorter than des 3 and those placed on anterior 289 third, $f_{s} 4, f_{s} 5$, des 5 , and $l e s 2$ ). Ephipharynx with spinules anteriad and posteriad to the labral 290 rods; epipharyngeal sensilla not in clusters but apparently fused into single units. Pronotum 291 pigmented with pattern of brownish maculae (Fig. 3A). Abdominal apex (AIX) with transverse 292 sclerotized ridges in dorsum, pleura and sternum (Fig. 3D).

293 Larva 1 (Figs. 2H-J, 3F). Maximum head width $0.2 \mathrm{~mm}$. Head (Fig. 2A) with des 1 minute (like 294 des 4), cephalic setae well developed are $\operatorname{des} 2, \operatorname{des} 3, \operatorname{des} 5, f_{s} 4, f_{s} 5$, les 1, and les2; des 1 slightly 295 more widely separated than $f_{s} 4$. Clypeus with setae subequal. Labrum with $\operatorname{lms} 2$ somewhat more 296 widely separated than $\operatorname{lms} 1$.

297

298 Type material examined. Lectotype of Canephorus vulcanorum Kirsch, female, Ecuador 299 Tunguragua, 3800, Canephorus vulcanorum typus Kirsch, MTD, (Fig. 4A), here designated. 300 Paralectotype of Canephorus vulcanorum, Ecuador, Sangay, 3500m, cotypus, MTD. Lectotype 301 of Amphideritus brevis Oliff, female, Ecuador feet, Ed. Whymper, MNHN, here designated (Fig. 302 4B). Lectotype of Amphideritus pigmaeus Oliff, female, Chimborazo, Ecuador, 12-13000 feet, 303 Ed Whymper, MNHN, here designated (Fig. 4C). Lectotype of Caulostrophus aequatorialis 304 Kirsch, female, Cotopaxi, 5688, Typus, MTD, here designated (Fig. 4D).

305

306 Other material examined. COLOMBIA. No loc., int. Miami, 5-2-85, with cut flowers of 307 Dianthus sp. (1f USNM). ECUADOR. No loc., 11-11-93 (2f USNM). Chimborazo:

308 Chimborazo, S side of Mt, elev 11600 nr Snowline, 19 june 1975 (1f USNM); Colta, 3-VI-05, 309 Ohaus, 9-VII-05 (27f ZMB); Interandin-Hochland, Colta 3500-4000m, 8-10-VII-1905 Ohaus (1f 310 ZMB), 2,8-VII-1905 Ohaus (2f ZMB); Faldas del Chimborazo, jan-1983, in pine leaves Pinus 311 radiata, adults feed, Lopez col (1f USNM); Guamote, 3-7-1969, en cocoons of alfalfa plants (1f 312 USNM); Guaslam prov, 1-22-60-on bucts of young corn, Merino (2f USNM); Quimiag on 313 maize, Jan 1979 Kirckhy (2f BMNH); Riobamba, 3-VII-1905, unter steinen, Ohaus (17f ZMB), 314 20-XI-05 (1f ZMB ), 27-XI-05 (2f ZMB); Riobamba, Ause de Cubillin, 3500, 5-Vii-05 Ohaus 315 (42f ZMB). Cotopaxi: $71 \mathrm{~km} \mathrm{~W}$ Latacunga under stones May 1, 1978, O’Brien \& Marshall (1f 316 1m MLP; 45 km W Latacunga, under stones May1 1978, O’Brien \& Marshall (8f MLPC); 21 km 
317 S Latacunga, April 25 1978, CW\&L O’Brien \& Marshall (1f MLP); 6 km W Latacunga, under 318 stones, May1 1978, O’Brien \& Marshall (3f MLP); Latacunga, XI 1981 Onore Brit Mus 1990319214 (1f BMNH); 15 km W entrance PN Cotopaxi, April 30 1978, O’Brien \& Marshall (4f MLP); 32014 km W entrance PN Cotopaxi, April 30 1978, O’Brien \& Marshall (1f MLP); Cotopaxi, P. 13 321 km S Latacunga along PanAma, XI-3-77, G Noonan, M. Moffett, under clumps soil and grass, 322 rocks, debris-in green grassy field w green short grass ca 2600m. (13f 1m MLP); Tilipulo, V-III323 1981, G. Onore Brit Mus 1985-254 (4f BMNH). Bolívar: Guaranda, X-I-1955, on new corn (7f 324 USNM). Loja. Loja, Ohaus (2f ZMB). Pichincha: 38.8km NE Quito on PanAm XI-8-77, G 325 Noonan, M. Moffett, under rocks on dirt clumps, in areas with sparse to very sparce short grass

326

327 328 329 ca 2200m. (1f MLP). Tungurahua: SE end Ambato, XI-1-77, G Noonan, M. Moffett, under rock in fields w short sparce grass, soil dry under stones, ca 2500m. (2f MLP); 13km NE Baños, April 26 1978, O’Brien \& Marshall (1f MLP); Baños, 1800m, 9-V-37 Brundage (2f USNM); Baños, X-4-44, EJ Hambleton (1f USNM); Pomasqui, X-7-54, Merino, orange trees (4f USNM); Totoras, 7 km SE Ambato, April 26 1978, O’Brien \& Marshall (3f MLP). Plus, the material listed in del Río, Marvaldi \& Lanteri (2012).

Remarks. In the revision of the genus Leschenius (del Rio, Marvaldi \& Lanteri, 2012), the type material of the species Asymmathetes aequatorialis (Kirsch) was not seen and we mentioned that this species may also belong to the genus Leschenius. Herein, based on the observation of the type material of all the names related to Leschenius vulcanorum (Fig. 4A-D), including Caulostrophus aequatorialis Kirsch (Fig. 4D), we establish the synonymy of this name with $L$. vulcanorum (Fig. 4A). This species is only known from the type material and corresponds to a phenotype within the great variation observed in L. vulcanorum (see Fig. 4A-D).

Bisexual populations of L. vulcanorum have been so far only seen in Ecuador, near Latacunga locality (Cotopaxi province), and in Ambato locality (Tungurahua province) (Fig. 7). Differences noted between the bisexual and the parthenogenetic populations are related with the body size and morphometrics of the elytra. The bisexual form is usually smaller with slightly shorter elytra.

Host plants. Leschenius vulcanorum was found in association with cabbage Brassica oleracea L. (Brassicaceae), alfalfa Medicago sativa L. (Fabaceae), young corn Zea mays L. (Poaceae), 
348 pine Pinus radiata D. Don, orange trees, and with cut flowers of carnation Dianthus sp. It is 349 considered an important pest of potato Solanum tuberosum L. (Solanaceae) in Colombia, and is 350 known as 'potato shooter' (del Rio, Marvaldi \& Lanteri 2012).

351

352 Leschenius ventrilingulatus del Río \& Marvaldi, sp. n.

353 urn:lsid:zoobank.org:act:9A70B8AE-74BF-4631-98A7-A1C814113833

354 (Figs 5B-F; 6A-F, H, L, 7)

355

356 Diagnosis. Leschenius ventrilingulatus is easily distinguished from the remaining species of

357 Leschenius (except $L$. vulcanorum) by possessing a shorter and less conical rostrum with sides

358 not thickened and elevated, and apex not projected. It is very similar to L. vulcanorum, but 359 distinguished by its size usually small, vestiture of denser and thicker setae (mainly on head, legs 360 and elytra), shorter antennae (with funicular segments 1 and 2 subequal); shape of the pronotum, 361 subcylindrical with anterior margin as wide as posterior margin; elytra shorter (about 1.5x longer 362 than wide at base; $2 \mathrm{x}$ in L. vulcanorum); the metatibial apex with narrow corbel; female with 363 ventrite 4 with a posterior rounded projection; and posterior margin of ventrite 5 subacute, not 364 excavated. Female genitalia with plate of sternite VIII sub-rhomboidal not elongate with longer 365 apodeme.

366

367 Description. Female (Figs. 5B, D-F). Species medium-sized (LB, 5.0-6.0 mm). Tegument 368 visible, dark brown to reddish brown, shiny. Vestiture composed of disperse, pale ocher to cream 369 colored setae, moderately dense, cream-colored decumbent setae-like scales, absent on middle of 370 pronotum (forming wide lateral stripes) on pronotum, grouped on patches on elytra, in some 371 cases devoid of scales along middle line; also present on venter and legs (more abundant on 372 distal third of femora). Rostrum very short (Fig. 5F) (L/Wa, 0.73-0.83), sides moderately 373 convergent towards apex ( $\mathrm{Wb} / \mathrm{Wa}, 1.31-1.43)$, dorsum moderately convex. Forehead foveolate374 strigose, with longitudinal striae. Vertex sparsely punctate. Antennae (Fig. 6A) of medium length 375 (LB/LA, 2.50-2.85); scape reaching to slightly exceeding posterior margin of eyes. Funicle with 376 segment 2 about as long as segment 1, both elongated; funicle segments 3-6 slightly longer than 377 wide, and funicle segment 7 as long as wide; club slightly fusiform (L/W, 2.3-2.4). Pronotum 378 (Fig. 5B) slightly subcylindrical, moderately wider than long (W/L, 1.30-1.35), with anterior 
379 margin as wide as posterior margin; median groove absent. Scutellar shield subtriangular, large 380 and wide (surrounded by elevated edges), denuded. Elytra (Fig. 5B, E) short (L/W, 1.23-1.33), 381 with maximum width on anterior third, slightly convex; base slightly curved backwards on 382 middle; intervals about twice as long as striae, flat; striae with medium-sized punctures, 9-10 383 slightly closer along posterior two-thirds; elytral apex acute not projected or bifurcate, entire. 384 Legs. Procoxae much closer to anterior than posterior margin of prosternum; protibiae with 385 medium-sized mucro, and row of acute small denticles (six or seven, on distal two-thirds of tibiae); meso- and metatibiae with small mucro and without denticles; metatibial apex with 387 narrow corbel covered with disperse small elongate cream scales; apical and dorsal combs 388 subequal. Abdomen (Fig. 5D). Intercoxal portion of ventrite 1 slightly broader than metacoxal cavities (1.10-1.15x); ventrite 2 longer than ventrites 3 and 4 combined (1.60x without projection; 1.10 along midline); ventrite 4 with a posterior rounded projection; posterior margin of ventrite 5 subacute, not excavated; tergites I-VII membranose. Terminalia. Sternite VIII (Figs. 6B-C) with plate sub-rhomboidal, not elongate, with tuft of medium-sized and coarse setae, and with shorter setae on apical third; ' $V$ '-shaped sclerotization with lateral arms reaching two-thirds of plate, and lateral margins sclerotized; apodeme 2.8-3.0x longer than plate. Ovipositor (Figs. $6 \mathrm{D}-\mathrm{E}$ ) as long as ventrites1-5; with scattered fine short setae on sides of baculi on anterior third; ventral baculi subparallel; styli wide. Spermathecal body (Fig. 6F) sub-cylindrical; collum (ductlobe) conical, short; ramus (gland-lobe) indistinct; cornu long; spermathecal duct (Fig. 6D) short, half as long as ovipositor, or $3 \mathrm{x}$ the maximum width of spermatheca, membranous, moderately wide.

400 Male (Fig. 5C). Same size as female (4.8-5.5 mm); rostrum less conical (Wb/Wa, 1.32-1.37); 401 antennal club more elongate (L/W, 2.6-2.7); elytra slightly more elongate (L/W, 1.30-1.35); 402 metatibia with larger mucro than in female; ventrite 4 without posterior projection; posterior 403 margin of ventrite 5 blunt. Genitalia (Figs. 6H, L). Penis (median lobe) slightly curved in lateral 404 view, tapering towards apex, with dorsad recurved hook-like apex; penis as long as abdomen; 405 penis apodemes slightly shorter than penis body $(0.8 \mathrm{x})$; endophallus armed with minute spicules 406 and with a sclerotized flagellum, with a denticulated blade (Fig. 6H).

407 Morphometrics. Holotype, female: rostrum L/Wa: 0.77, Wb/Wa: 1.31; antenna LB/LA: 2.85, 408 antennal club L/W: 2.31; pronotum W/L: 1.34; elytra L/W: 1.33; LE/LP: 2.6. 
410 Etymology. The specific name refers to the tongue-like projection of the female venter.

411

412 Material examined. Holotype. Female, $5 \mathrm{~mm}$ long, with labels as follows "ECUADOR, 413 Totoras,/ 7km SE. Ambato/Apr. 26, 1978 C\&L/ O’Brien \& Marshall” (MLPC). Paratypes. 414 Same data as holotype (1m ASUCOB); ECUADOR, $6 \mathrm{~km} \mathrm{~W} /$ Latacunga under/ stones May 1, 415 1978/ O'Brien \& Marshall (1f, 1m MLP, dissected with genitalia in vial with glicerine); 416 ECUADOR/ Latacunga/ IX- 1981 Onore/ Brit. Mus./ 1990-214 (3f 2m BMNH); ECUADOR, $4175 \mathrm{~km}$ SE./ Pelileo, April/ 26, 1978 CW\&LB/ O'Brien \& Marshall (1m ASUCOB); ECUADOR/ 418 Catamayo B./ Loja 5.9.05/ F. Ohaus (1f ZMB).

419

420

421

422

423

424

425

426

427

428

429

430

431

432

433

434

435

436

437

438

439

Geographic distribution (Fig. 7). Leschenius ventrilingulatus is endemic of Ecuador, known for Cotopaxi, Loja, and Tungurahua provinces. It is distributed on the interandean region on river basins, between 1250 and 2750 meters above sea level (unlike L. vulcanorum which is distributed in higher altitudes $2600-5000$ m. a. s. 1.). It is sympatric with $L$. vulcanorum (Fig. 7) in Latacunga (Cotopaxi province) and Totoras (Tungurahua province) at 2600-2750 m. a. s. 1.

Remarks. Leschenius ventrilingulatus is the sister species of $L$. vulcanorum, according to results of the cladistic analysis herein undertaken (Fig. 1).

\section{Leschenius bifurcatus del Río, Marvaldi \& Lanteri 2012} (Figs 5G-H, 6 I, J, M, 7)

Diagnosis and description of female in del Río, Marvaldi \& Lanteri (2012).

Description of male (Fig. 5H). Similar size as female, slightly smaller (Fig. 5G) (10-13 mm); rostrum (L/Wa, 1.0-1.1; Wb/Wa, 1.30-1.45); antennal club slightly more elongate (L/W, 3.13.4); pronotum (W/L, 1.17-1.19); elytra (L/W, 1.60-1.65) with projected apex but not bifurcated, only slightly divided; ventrites 3-5 not bulged as female, posterior margin of ventrite 5 blunt. Genitalia (Figs 6I, J, M). Penis body slightly curved in lateral view, tapering towards apex (Fig. 6M), with dorsad strongly recurved hook-like apex (Fig. 6J); penis longer than 
440 abdomen (1.25-1.30); penis apodemes much shorter than median lobe (0.4x); endophallus armed 441 with minute spicules and with two long wing-shaped sclerites (Fig. 6I).

442

443 Material examined. ECUADOR. No loc, intercept. Port Miami, 16-VI-2004 (1f USNM).

444 Imbabura: $3.9 \mathrm{~km}$ N. Ibarra on Pan Am, XI-II-77, Moffet collr, under rocks by rd. in dry area, 445 with sparce grass ca. 2300 (1f, 3m ASUCOB; 1f, 2m MLPC;); Urcuqui, 14-III-62, Merino \& 446 Vasquez, in soil nr cotton plants (2m USNM); El Chotar, Mr. Juncal, 1 june-1961, Merino \& 447 Vasquez, reared from larvae doing damage to roots of bean plants (1m USNM). Pichincha: 448 Conocoto, 31-Jan-1992, Alvaro Barragan (1m MLP); Pomasqui, Runicucho, 2400 m., 6 Dec449 1993, E. Volbracht (1m PUCE). Plus the material listed in del Río, Marvaldi \& Lanteri (2012). 450

451 Remarks. The specimens of the population from Ibarra (Imbabura) are slightly different from 452 the type, the female (Fig. 5G) has a wider and shorter pronotum and the elytral apex only slightly 453 bifurcated but strongly projected posteriad; the males have also a wider and shorter pronotum 454 and the penis with a shorter ostium area and a more recurved apex (Fig. 6J). 455

Host plants. The larvae of L. bifurcatus was found in association with bean plants, Phaseolus vulgaris L. (Fabaceae).

458

\section{Key to species of Leschenius}

Modified from del Río, Marvaldi \& Lanteri (2012).

461

462

1. Size 4-8 mm (usually 5-7 $\mathrm{mm}$, exceptionally more than $8 \mathrm{~mm}$ but never more than $9 \mathrm{~mm}$ ); rostrum very short (L/W less than 0.95 , usually near 0.8 ); pronotum with setae forming two feeble lateral stripes; elytral apex not projected.

$1^{\prime}$. Size 8-12.5 mm; rostrum moderately short (L/W more than 0.96 , usually 1 ); pronotum without or with scattered setae, never forming lateral stripes; elytral apex projected backwards. .3

2. Elytra with cream-colored decumbent setae like scales grouped on patches on entire elytra; pronotum subcylindrical, with anterior margin as wide as posterior margin; metatibial apex 
470

471

472

473

474

475

476

477

478

479

480

481

482

483

484

485

486

487

488

489

490

491

492

493

494

495

496

497

498

499

500

with narrow corbel; female with ventrite 4 with a posterior rounded projection (Fig. 5D)....

2'. Elytra devoid of cream-colored decumbent setae like scales, or if present, limited to margins (intervals 9-10); pronotum slightly subconical, with posterior margin wider than anterior margin; metatibial apex with moderately broad corbel (width: 1/3 of the length of the tibial apex); female with ventrite 4 without posterior projection

L. vulcanorum (Figs. 4A-D, 5A, see fig. 1 in del Río, Marvaldi \& Lanteri, 2012)

3. Pronotum with posterior margin as wide as anterior margin; elongate elytra (3x or more the length of pronotum); elytral apex, in females strongly projected backwards and distinctly bifid or divided; in males, moderately projected and rounded to slightly divided.

L. bifurcatus (see figs. 2-3 of del Río, Marvaldi \& Lanteri, 2012)

3'. Pronotum with posterior margin distinctly wider than anterior margin; oval elytra (less than
$2.8 \mathrm{x}$ the length of pronotum, usually between 2.2-2.7x); elytral apex of both males and

females moderately projected, entire to slightly divided. 4

4. Corbel plate of metatibia broad (width: almost half the diameter of apex of tibiae).

...................................... L. nigrans (see figs. 9-10 of del Río, Marvaldi \& Lanteri, 2012)

4'. Corbel plate of metatibia narrow (less than quarter apex of tibiae).......................5

5. Body length 8.4-9.3 mm, moderately sized; pronotum as wide as elytra in males; elytra 2.2-

$2.45 \mathrm{x}$ the length of pronotum; spermatheca with collum not constricted.

5'. Body length 7.8-8.4 mm, small; pronotum distinctly narrower than elytra in both sexes; elytra 2.5-2.75x the length of pronotum; spermatheca with tubular collum, constricted near spermathecal body...L. silviae (see figs. 11-12 and 42 of del Rio, Marvaldi \& Lanteri, 2012)

6. Pronotum slightly wider than long (W/L: 1.10-1.25); ovipositor without setae on sides of baculi; apex of penis slightly pointed

4

6'. Pronotum of males strongly wider than long (W/L: 1.30-1.35); ovipositor with conspicuous setae on sides of baculi; apex of penis rounded.

Dis

\section{Discussion}


501

502 The cladistic analysis led us to uncover evidence for the monophyly of the genus Leschenius and

503 for the relationships among its species. It is worth to note that Asymmathetes pascoei is

504 supported as the sister group of Leschenius, in agreement with del Río, Marvaldi \& Lanteri

505 (2012), but differing from results of the analysis by Lanteri \& del Río (2017): (Asymmathetes

506 (Amphideritus (Leschenius (Amitrus (Obrieniolus (Melanocyphus, Trichocyphus)))))). However,

507 this is not unexpected as these works had different objectives and thus differ in the taxon and

508 character sampling (e.g. in the analysis of Lanteri \& del Rio there is only one species

509 representing the genus Leschenius and, on the other hand, the present study was not designed to

510 test intergeneric relationships). Further research on the systematics and phylogeny of the

511 "Andean Group" will require expanding the outgroup and ingroup taxon sampling (e.g.,

512 including Obrienolus and more species representative of each genera) and using additional

513 sources of evidence like molecular data.

514 The description of a new species and more complete information about male characters,

515 allowed us to propose an updated phylogenetic hypothesis of Leschenius, which differs from the

516 previous study by del Río, Marvaldi \& Lanteri (2012) regarding the position of L. bifurcatus and

517 relationships within clade B (Fig. 1). In the new phylogeny L. bifurcatus is the sister species of a

518 subclade that contains L. nigrans sister of L. silviae and L. rugicollis sister of L. manueli. Also,

519 the present study led to the discovery of the sister species of $L$. vulcanorum and the pair $L$.

520 ventrilingulatus - L. vulcanorum is proposed as the sister group of all remaining species of

521 Leschenius.

522 Leschenius is distributed in the northern Andes of Ecuador and northern Colombia,

523 approximately 1800-5000 m.a.s.1 (Fig. 7), corresponding to the Páramo province of the South

524 American Transition Zone (Morrone, 2014). All species included have a narrow distribution

525 range in Ecuador, except L. vulcanorum that is widely distributed from central to northern

526 Ecuador and extend to southern Colombia. The latter species, L. vulcanorum, along with $L$.

527 ventrilingulatus, L. bifurcatus, and L. nigrans inhabit in northern Ecuador, and they have been

528 found in sympatry (Fig. 7). The other three species, L. silviae, L. manueli, and L. rugicollis are

529 distributed in the southern provinces of Ecuador. The new species L. ventrilingulatus is

530 distributed on the inter-Andean region on river basins (Fig. 7) and is sympatric with $L$.

531 vulcanorum at 2500-2750 m.a.s.1., that corresponds to the lowest altitude for L. vulcanorum.

Peer] reviewing PDF | (2021:11:67992:2:0:NEW 12 Jan 2022) 
533 and this mode of reproduction was suggested by del Rio, Marvaldi \& Lanteri (2012) for the

534 species L. vulcanorum and L. bifurcatus, based on the apparent absence of males in their

535 populations. The examination of additional material in the present study provided new evidence

536 that suggest L. bifurcatus is not parthenogenetic, leaving Leschenius vulcanorum as the only

537 parthenogenetic species. The parthenogenesis of L. vulcanorum was confirmed by laboratory

538 rearing of unmated females that produced viable offspring (del Río, Marvaldi \& Lanteri, 2012).

539 Nonetheless, in the present study, we discovered males of L. vulcanorum, indicating that this

540 species also has bisexual populations, so far only seen in three localities in Cotopaxi and

541 Tungurahua provinces of Ecuador. The existence of both sexual and parthenogenetic populations

542 within the species supports the idea of a special kind of parthenogenesis, called "geographical

543 parthenogenesis" (Lanteri \& Normark, 1995). In L. vulcanorum, as in other species having this

544 kind of reproduction, the sexual and parthenogenetic forms have different distribution ranges,

545 being the parthenogenetic one more widespread than the respective sexual forms (Vandel, 1931).

546 So far, exemplars of both sexes of this species were collected in just three localities.

547 Morphological differences between the bisexual and the parthenogenetic form are noticed in

548 body size and morphometrics of the elytra, being the bisexual form usually smaller and with

549 slightly shorter elytra. It is important to remark that within the parthenogenetic form the variation

550 in body size and morphometrics is extremely wide (Figs. 4A-D). Same as other parthenogenetic

551 weevils, including the around 30 parthenogenetic species of the tribe Naupactini (Lanteri \&

552 Normark 1995), in L. vulcanorum the parthenogenesis is also associated with the wingless

553 condition and xeric habitats.

554 An interesting feature observed in females of the new species described, $L$.

555 ventrilingulatus (sexually dimorphic) is the ventrite 4 with its posterior margin produced

556 medially into a tapered lamina or tongue-like projection. This characteristic seems to be unique

557 within the tribe Naupactini, and so far, also unknown among Neotropical Entiminae. Although

558 unusual, a modified ventrite 4 is also present in genera of Entiminae inhabiting montane areas of

559 other regions of the word (see Brown, 2017 and reference therein): New Zealand

560 [Austromonticola Brown 2017, Chalepistes Brown 2017, and Nicaeana Pascoe 1877], Solomon

561 Islands [Platyacus Faust, 1897 (Celeuthetini)], Mauritian Islands [Syzygops Schönherr, 1826

562 (Ottistirini)]; Chinese Himalayas [Trichalophus caudiculatus (Fairmaire, 1886) (Tropiphorini)], 
563 Kashmir and Himalayas [Leptomias Faust, 1886 (Tanymecini)], and Central

564 America [Sciomias Sharp, 1911 (Sciaphilini)]. These structures are hypothesized to have evolved

565 in response to oviposition needs in and beside cushion plants or selected to mitigate the female

566 costs of prolonged mating (Brown, 2017). Although the function has not been studied yet, the

567 first suggestion that these ventral structures may assist in the preparation of oviposition sites in

568 close-packed vegetational structures seems highly plausible: the cushion growth form is a

569 common feature of the alpine vegetation worldwide where the weevil species with this trait are

570 found.

571 Concerning the immature stages, the study of the larvae of Leschenius lead us to confirm

572 that the tribe Naupactini is very homogeneous in larval morphology, as suggested by Marvaldi

573 (1998). Also, there seem to be no particular features that could be suggestive as adaptive traits to

574 arid environments. This is not unexpected, since Leschenius larvae, like those of most entimines,

575 are subterranean and then "preadapted" to live in harsh environments.

$576 \quad$ Finally, additional research with molecular tools will be very important to find out the 577 genetic divergence and evolution of the group, and the role of the parthenogenesis. Moreover, 578 the study of the biology and behavior of L. ventrilingulatus will offer insights into the function of 579 the abdominal structures of the female.

580

581

582

583

584

585

586

587

588

589

590

591

592

593

594

\section{Acknowledgements}

We thank all the specialists and curators that loaned us specimens for study and/or facilitated the examination of the material in their collections.

\section{References}

Brown SD. 2017. Austromonticola, a new genus of broad-nosed weevil (Coleoptera, Curculionidae, Entiminae) from montane areas of New Zealand. ZooKeys 707: 73. del Río MG, Marvaldi AE, Lanteri, A. 2012. Systematics and cladistics of a new Naupactini genus (Coleoptera: Curculionidae: Entiminae) from the Andes of Colombia and Ecuador. Zoological Journal of the Linnean Society 166: 54-71.

Farris JS. 1989. The retention index and the rescaled consistency index. Cladistics 5: 417-419. 
595 Felsenstein J. 1985. Confidence limits on phylogenies: An approach using the bootstrap.

596 Evolution 39: 783-791.

597 Goloboff PA, Catalano S. 2016. TNT version 1.5, including a full implementation of phylogenetic

598 morphometrics. Cladistics 32(3): 221-238. DOI 10.1111/cla.12160.

599 Harris RA. 1979. A glossary of surface sculpturing. Occasional papers in Entomology 28: 1-31.

600 Kluge AG, Farris JS. 1969. Quantitative phyletics and the evolution of anurans. Systematic

601 Biology 18: 1-32.

602 Lanteri AA, del Río MG. 2017. Phylogeny of the tribe Naupactini (Coleoptera: Curculionidae)

603 based on morphological characters. Systematic Entomology 42: 429-447.

604 Lanteri AA, Normark BB. 1995. Parthenogenesis in the tribe Naupactini (Coleoptera:

605 Curculionidae). Annals of the Entomological Society of America 88: 722-731.

606 Lyal CHC. (Ed.) Glossary of Weevil Characters. International Weevil Community

607 Website. Available at http://weevil.info/glossary-weevil-characters (accessed November 10, 608 2021).

609 Marvaldi AE. 1998. Larvae of South American Entimini (Coleoptera: Curculionidae), and

610 phylogenetic implications of certain characters. Revista Chilena de Entomología 25: 21-44.

611 Marvaldi AE, Loiácono MS. 1994. First instar larvae in the tribe Naupactini (Coleoptera:

612 Curculionidae). Revista Brasileira de Entomologia 38: 453-466.

613 Marvaldi AE, Lanteri AA, del Río MG, Oberprieler RG. 2014. Chapter 3.7.5 Entiminae

614 Schoenherr, 1823. In: Leschen RAB, Beutel RG, eds. Handbook of Zoology. Arthropoda:

615 Insecta: Coleoptera, Beetles. Volume 3: Morphology and systematics (Phytophaga). Berlin: de 616 Gruyter, 503-523.

617 Morrone JJ. 2014. Biogeographical regionalisation of the Neotropical region. Zootaxa 3782: 1618110.

619 Nixon KC. 2002. WinClada, version 1.00. 08. Ithaca, NY, Published by the author.

620 Vandel A. 1931. La parthenogenese. Paris: G. Doin. 
Figure 1

MP tree for the genus Leschenius plus five outgroups members of the Andean Clade sensu Lanteri \& del Rio (2017).

The MPT shows the phylogenetic position of the new species, Leschenius ventrilingulatus.

Black circles homology, white circles homoplasy. Numbers below branches are $>50 \%$

Bootstrap values.

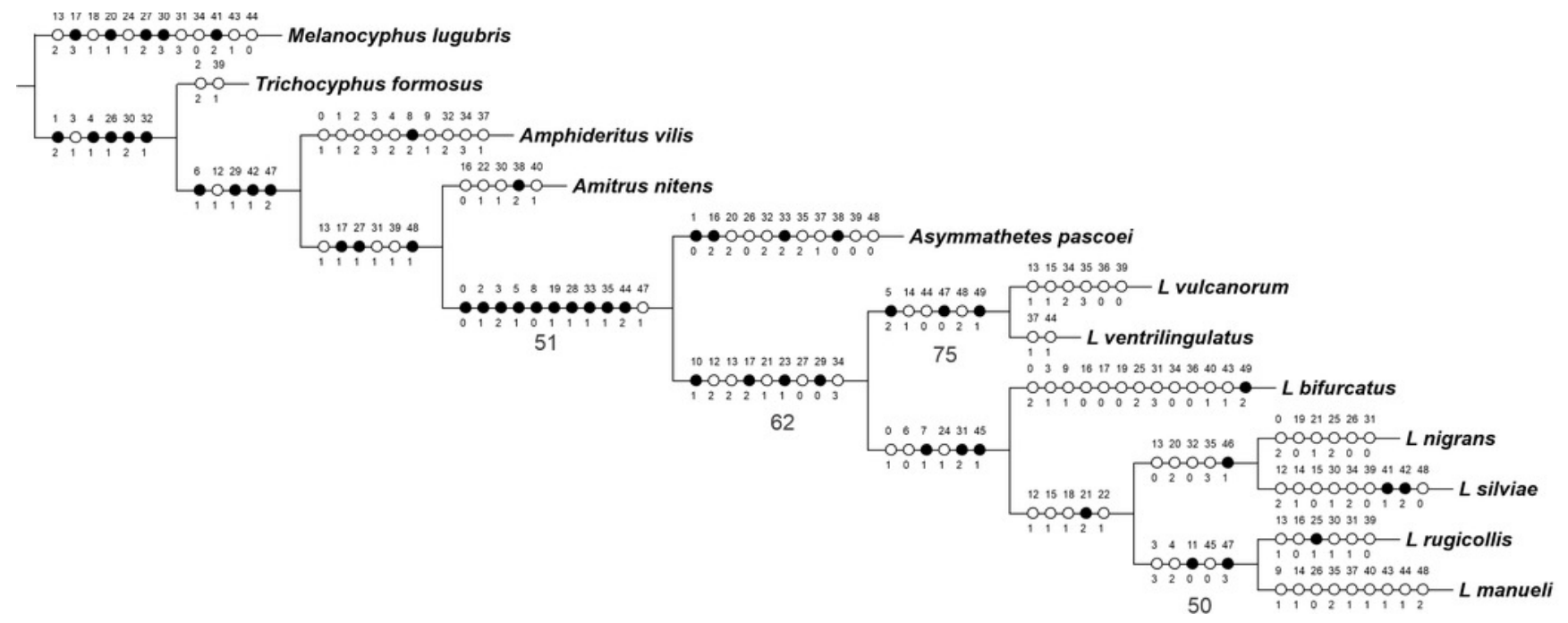


Figure 2

Leschenius vulcanorum, larvae. Head morphology.

(A-G) Mature larva. (A) Head, dorsal. (B) Left antenna. (C) Clypeus and labrum. (D)

Epipharynx. (E) Mandible, dorsal. (F) Maxilla and labium, ventral. (G) Maxilla, dorsal. (H-J)

First instar larva. (H) Head, dorsal. (I) Head, partial, ventral. (J) Mandible, dorsal. Scales A, $C-G=0.5 \mathrm{~mm} ; \mathrm{B}, \mathrm{H}-\mathrm{J}=0.1 \mathrm{~mm}$. 


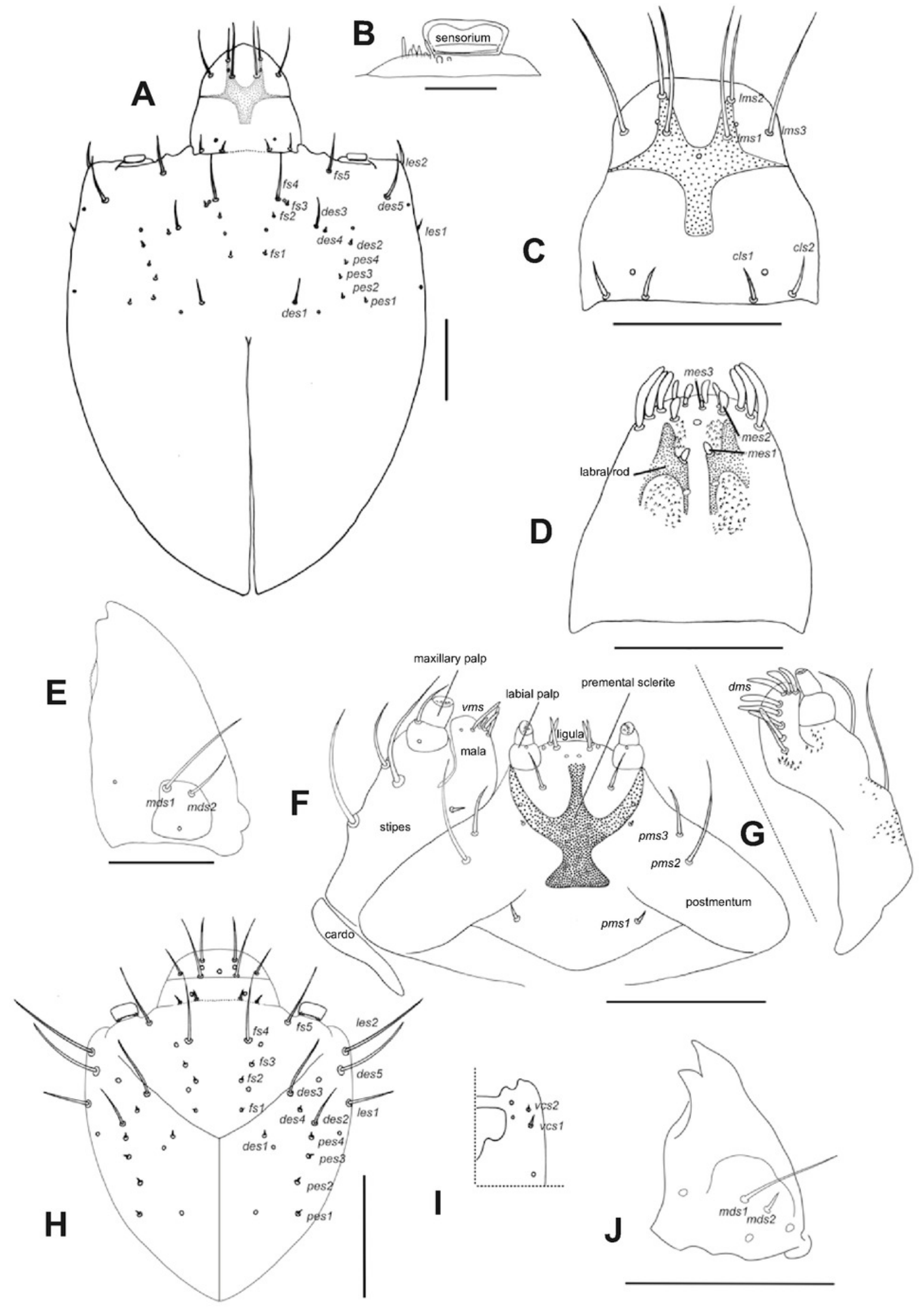




\section{Figure 3}

Leschenius vulcanorum, larvae. Thoracic and abdominal morphology.

(A-E) Body parts and chaetotaxy, mature larva. (A) Prothorax, mesothorax, metathorax and abdominal segment I, one side from mid-dorsum to mid-ventral. (B) Detail of pedal area. (C) Abdominal segment IV, dorso-lateral parts. (D) Abdominal apex, segments IX and X, caudal view. (E) Spiracles from thorax and abdominal segments I, IV and VIII. (F) Spiracles from thorax and abdominal segments I, IV and VIII, first instar larva. Scales A-D =1mm, $\mathrm{E}=0.5 \mathrm{~mm} ; \mathrm{F}=0.1 \mathrm{~mm}$. 

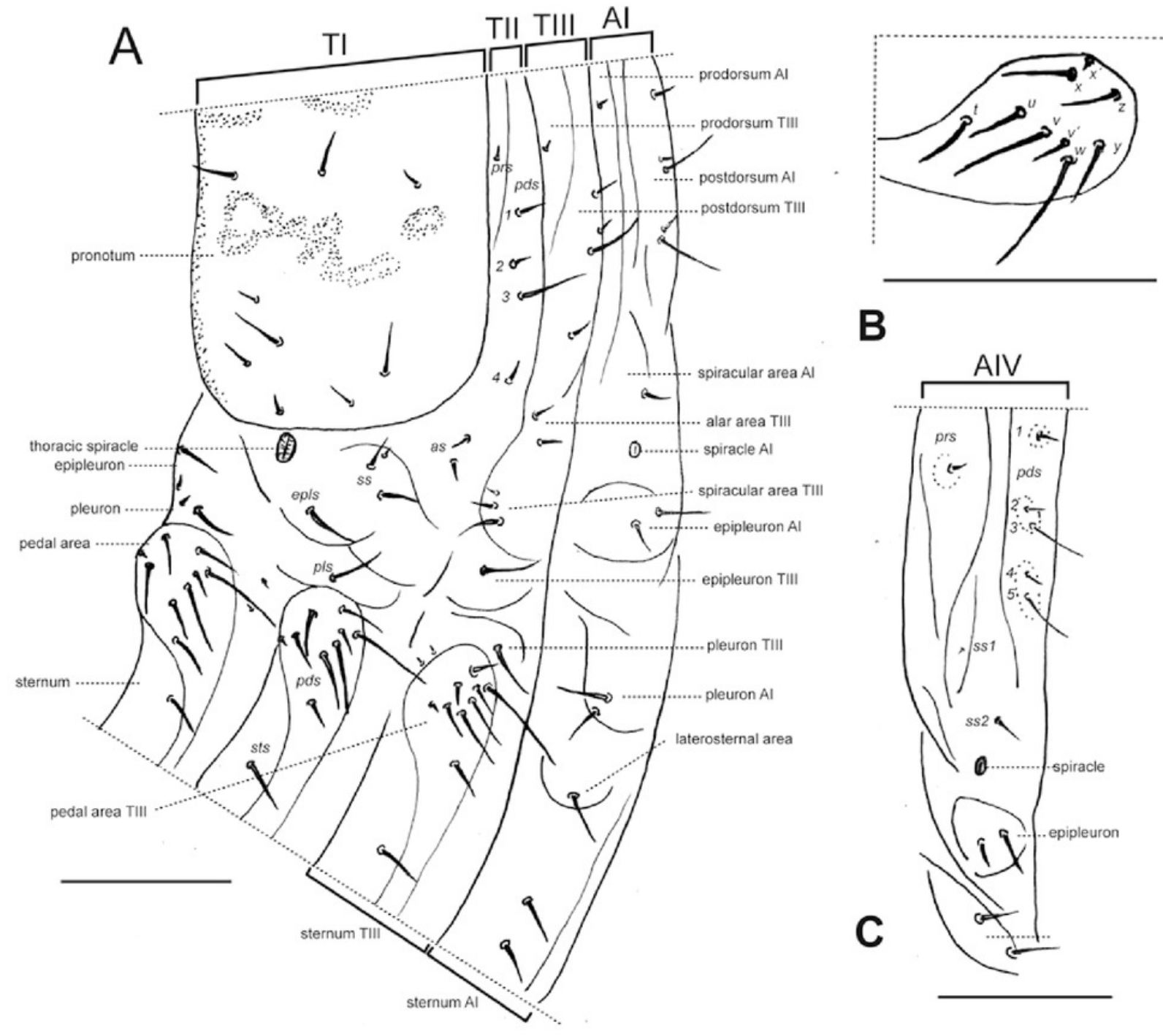

B
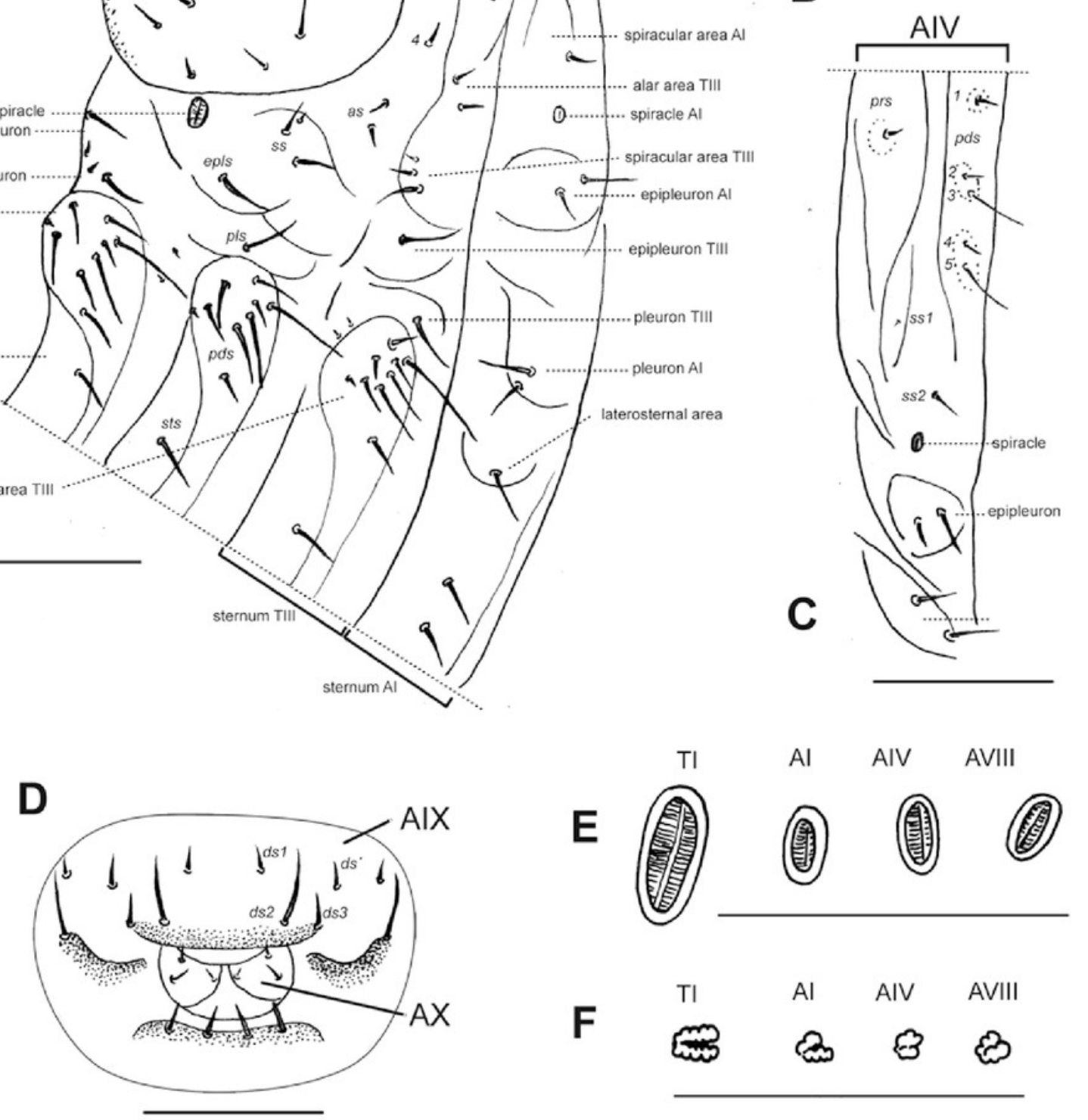

E 整

Al AIV AVIII

F $\quad \begin{array}{llll}\text { TI } & \text { AI } & \text { AIV } & \text { AVIII } \\ \text { की है है } & \text { हु }\end{array}$ 
Figure 4

Types, females, corresponding to the four species names of Leschenius vulcanorum.

(A) Lectotype of Canephorus vulcanorum Kirsch 1889, MTD. (B) Lectotype of Amphideritus brevis Oliff 1891, MNHN. (C) Lectotype of Amphideritus pigmaeus Oliff 1891, MNHN. (D) Lectotype of Caulostrophus aequatorialis Kirsch 1889, MTD. Scales 1mm. 

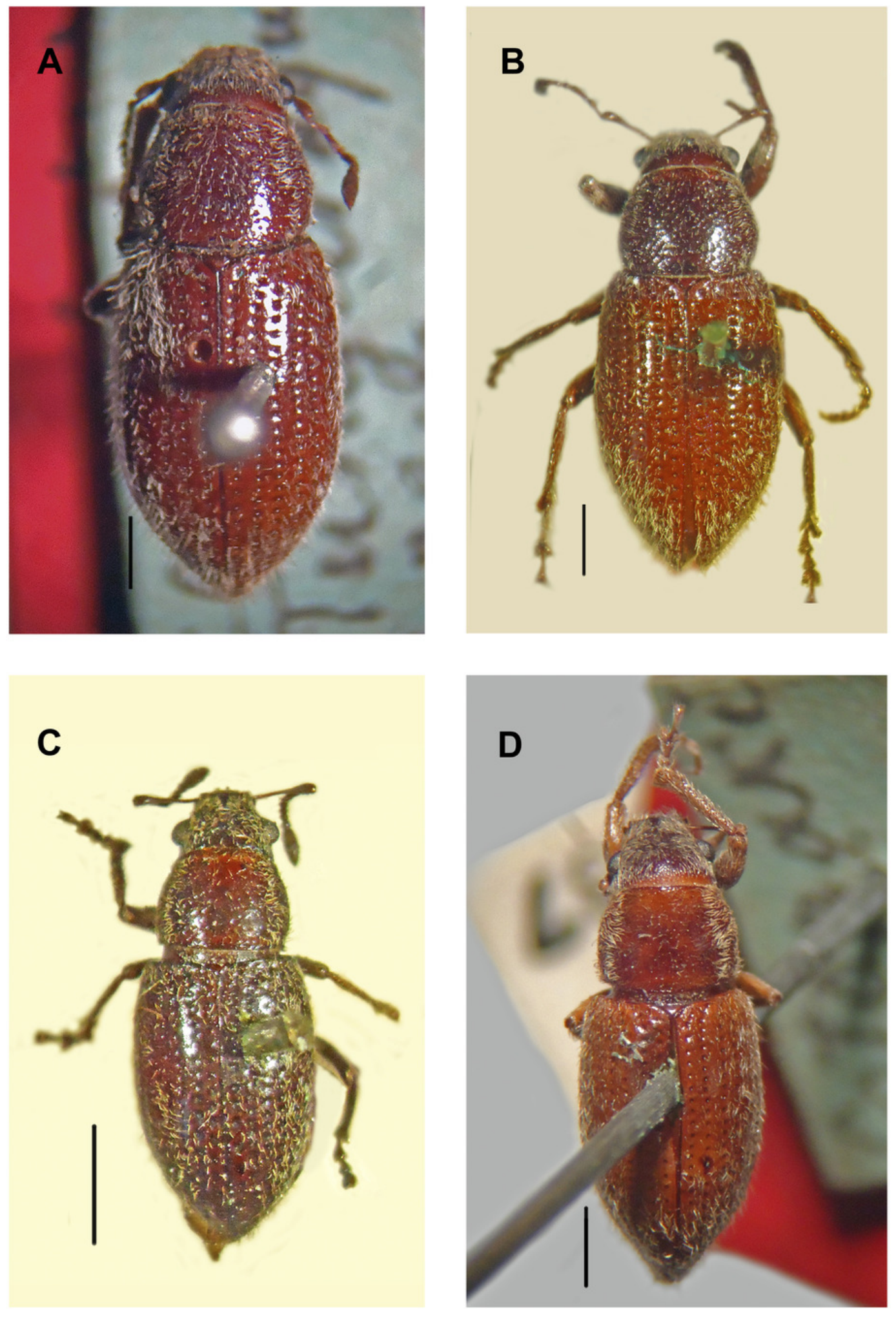


\section{Figure 5}

Photographs of Leschenius species.

(A) Leschenius vulcanorum, male, habitus dorsal view. (B-F) Leschenius ventrilingulatus $s p$.

nov. (B) holotype female, habitus dorsal view. (C) Paratype male, habitus dorsal view. (D) Holotype female, ventral view. (E) Holotype female, habitus lateral view. (F) Holotype female, head, frontal view. (G-F) Leschenius bifurcatus. (G) Female, habitus dorsal view. (H) Male, habitus dorsal view. Scales $1 \mathrm{~mm}$. 

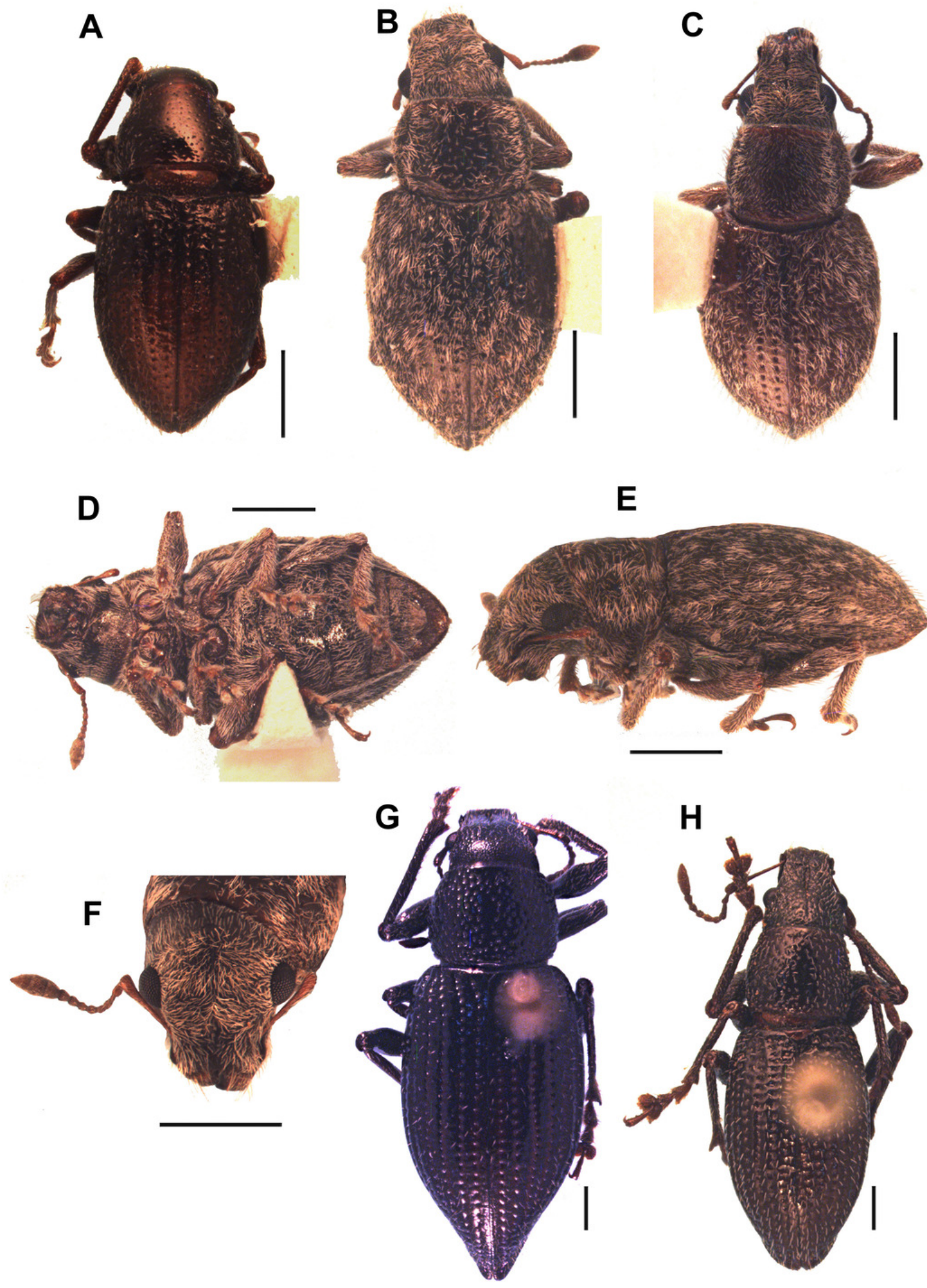

E

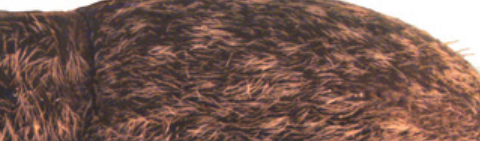

(19)
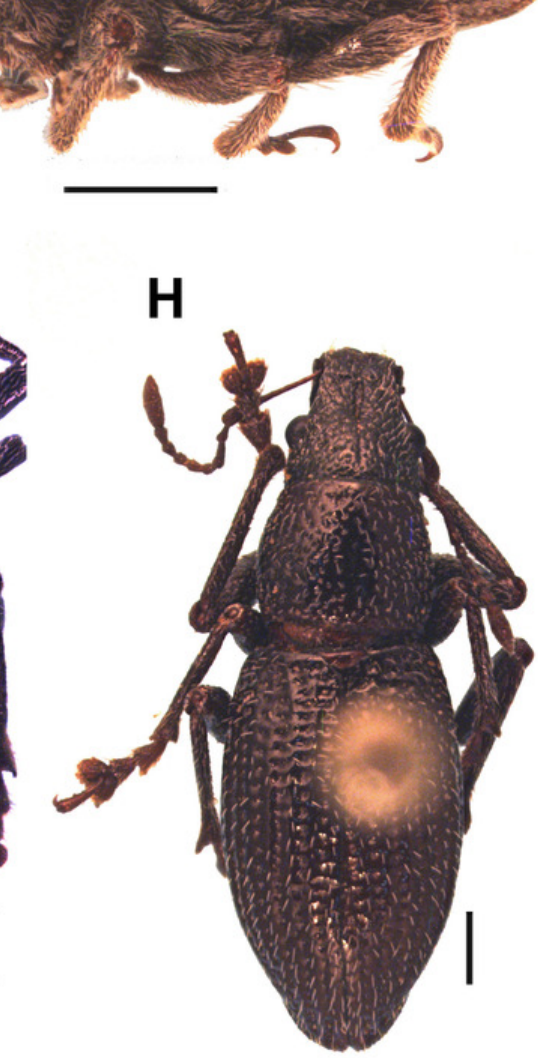


\section{Figure 6}

Morphological characters, and female terminalia of Leschenius ventrilingulatus, and male terminalia of Leschenius species.

(A-F) Leschenius ventrilingulatus. (A) Female, left antenna. (B) Female, sternite VIII. (C) Detail of plate of sternite VIII. (D) Female genitalia, ventral view. (E) Detail of distal third of ovipositor. (F) Spermathecae with spermathecal duct. (G-I) Aedeagus, lateral view. (J) Detail of apex, lateral view, left: phenotype from Imbabura, right: typical phenotype. (K-M) terminal portion of tube, ventral view. $(G, K) L$. vulcanorum. $(H, L) L$. ventrilingulatus. $(I, J, M) L$. bifurcatus. Scales $1 \mathrm{~mm}$. 

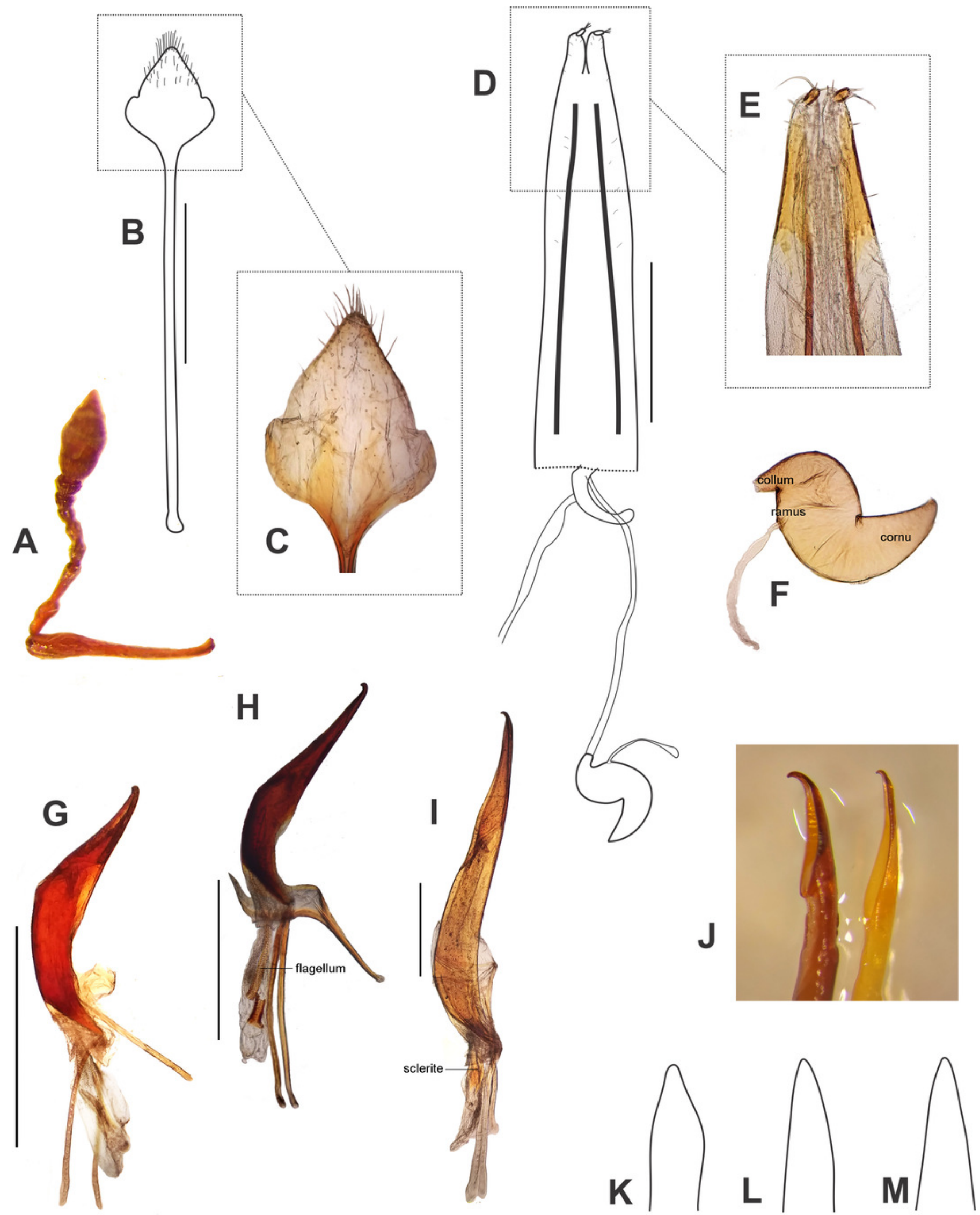


\section{Figure 7}

Distribution map of the seven species of Leschenius.

Ecuador and southern Colombia are shown in detail. Species references: L. nigrans, white circle; L. rugicollis white square; L. vulcanorum, parthenogenetic form white ellipse, bisexual form grey ellipse; L. manueli white triangle; L. bifurcatus black star; L. silviae black triangle; L. ventrilingulatus white star.

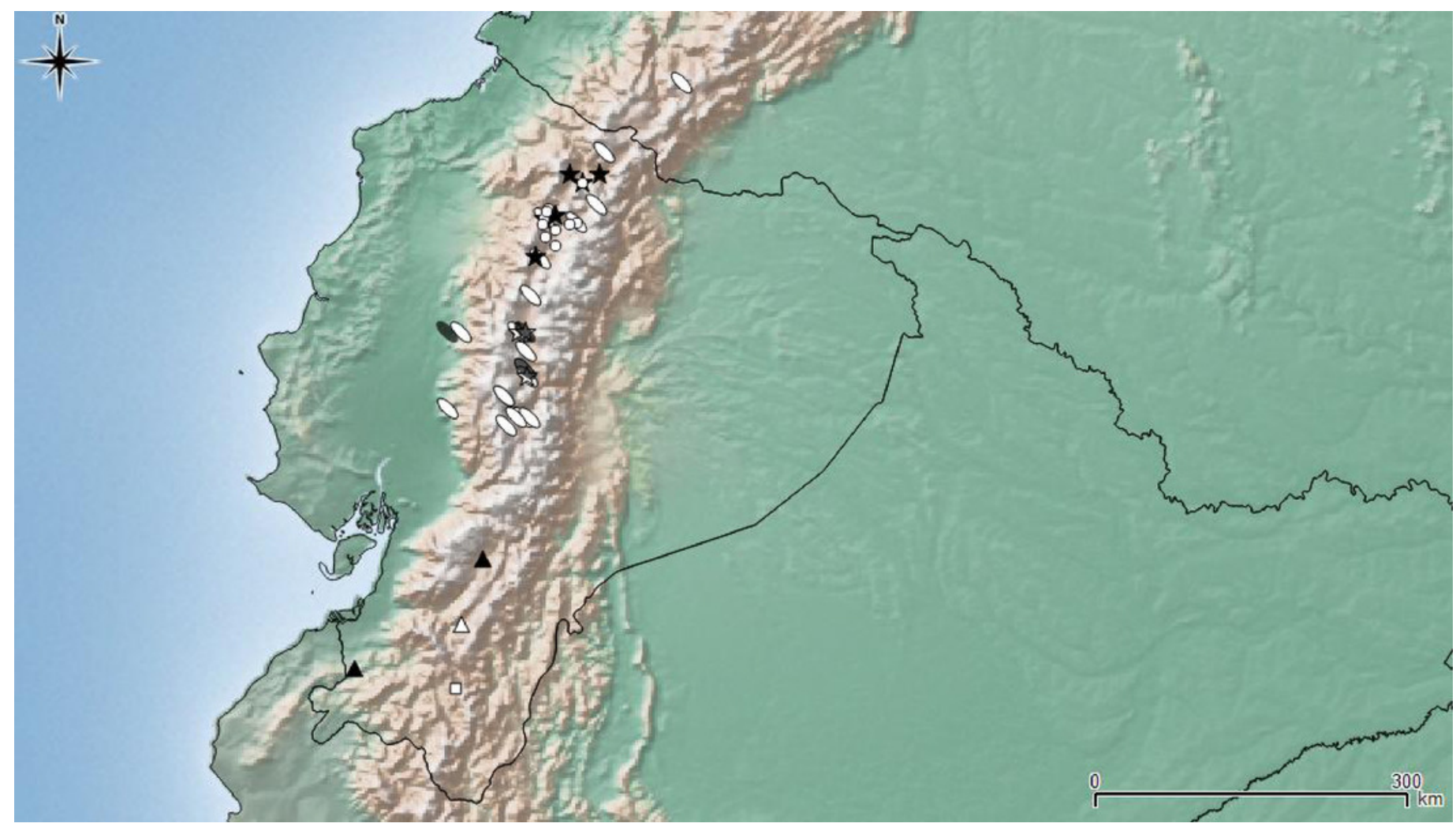




\section{Table 1 (on next page)}

List of characters, character states and coding. 


\section{External morphology}

0. Body size (length in dorsal view, from apex of rostrum to apex of elytra): small (less than 8 $\mathrm{mm}$ long) (0); medium sized (between 8-10 mm) (1); large (over $10 \mathrm{~mm}$ long) (2).

1. Elytral vestiture: squamose (0); setose (1); scarce or absent (2).

2. Elytral setae: absent (0); short, suberect (1); long, erect (2).

3. Rostrum and forehead: smooth (0); punctuate or foveolate (1); foveolate-strigose (2); coarsely strigose (3).

4. Pronotum: smooth (0); punctuate or foveolate (1); foveolate-granulose (2); tuberculate (3).

5. Relative length of rostrum: LR\WRa more than 1 (0); LR $\backslash W R a 0.96-1(1)$ less than 0.95 (2).

6. Sides of rostrum: slightly convergent towards apex (WRb $\backslash W R a$ less than 1.4) (0); moderately convergent towards apex (WRb $\backslash$ WRa more than 1.4) (1).

7. Rostral sulcus: reaching forehead (0); exceeding posterior margin of eyes (1).

8. Size of epistome: narrow (0); moderately wide (1); very wide (2).

9. Epistome: depressed (0); elevated (1).

10. Pre-epistome: absent or reduced (0); well developed (1).

11. Eyes: strongly convex (0); moderately convex (1).

12. Length of antennal scape: short, not reaching posterior margin of eyes (0); reaching posterior margin of eye (1); slightly exceeding posterior margin of eyes (2).

13. Ratio between length of funicle segments 2 and 1: La2/La1 more than $1.5(0)$; between 1.1 and 1.49 (1); subequal (2).

14. Ratio between maximum width and length of pronotum: W/L: less than $1.3(0)$; more than $1.3(1)$.

15. Shape of pronotum: subcylindrical (0); slightly conical (1).

16. Sides of pronotum: almost straight to slightly curved (0); moderately curved (1); strongly curved (2).

17. Pronotal base: straight (0); curved backwards (1); "V" shaped (2); bisinuate (3).

18. Projection of lateral angles of pronotum of males: absent (0); present (1). 
47

48

49

50

51

52

53

54

55

56

57

58

59

60

61

62

63

64

65

66

67

68

69

70

71

72

73

74

75

76

77

78

79

80

81

82

83

84

85

86

87

88

89

90

91

92

19. Ratio between maximum length and width of elytra: L/W more than $1.5(0)$; less than 1.5 (1).

20. Maximum width of elytra: about middle (0); at posterior third (1); at anterior third (2).

21. Elytral base: bisinuate (0); straight to slightly curved backwards (1); strongly curved backwards (2).

22. Humeral angles of males: not projected (0); anteriorly projected (1).

23. Elytral humeri: moderately prominent (0); slightly prominent to absent (1).

24. Apical projection of elytra: absent (0); present (1).

25. Elytral apex: entire (0); slightly divided (1); strongly divided or bifid (2).

26. Elytral intervals, width: slightly wider than striae (1.5-2x) (0); about same width of striae or slightly slender (1).

27. Elytral intervals, convexity: flat to slightly convex (0); moderately convex (1); strongly convex (2).

28. Procoxae, separation: contiguous to slightly separate (0); distinctly separate from each other (1).

29. Procoxae, position: almost contiguous with anterior margin of prosternum (0); about $2 \mathrm{x}$ closer to anterior than to posterior margin (1); less than $2 x$ closer to anterior than to posterior margin of prosternum (2).

30. Row of denticles on inner margin of tibiae: present on three pairs of tibiae (0); present on pro- and mesotibiae (1); present only on protibiae (2); absent on three pairs of tibiae (3).

31. Corbel of metatibial apex: broad, squamose (0); narrow to moderately broad, squamose (1); narrow, setose or denuded (2); absent (3).

32. Apical setal comb of metatibiae: longer than dorsal comb (0); about as long as dorsal comb (1); shorter than dorsal comb (2).

33. Ratio between length of ventrite 2 and ventrites $3+4$ (L2/L3+4); subequal (0); between 1.25 1.5 (1); more than $1.5 \mathrm{x}(2)$.

34. Posterior margin of of ventrite 5 in females: rounded (0); blunt (1); escavate (2); slightly pointed (3).

35. Posterior margin of ventrite 5 in males: rounded (0); bilobated (1); emarginate (2) blunt (3).

Peer] reviewing PDF | (2021:11:67992:2:0:NEW 12 Jan 2022) 


\section{Female terminalia}

36. Plate of female sternite VIII: subrhomboidal, elongate (basal half longer than apical half) (0); subrhomboidal, not elongate (basal and apical half subequal) (1).

37. Apodeme of female sternite VIII: less than $2.7 x$ longer than plate $(0)$; more than $2.7 x$ longer than plate (1).

38. Ovipositor: about as long as to longer than ventrites $1-5(0) ; 2 \backslash 3$ to $3 \backslash 4$ length of ventrites 1 5 (1); about $1 \backslash 2$ or less the length of ventrites $1-5$ (2)

39. Rows of setae along sides of baculi (ovipositor): absent (0); present (1).

40. Lenght of spermathecal duct: as long as half of the length of ovipositor (=medium-sized) (0); shorter than half of the length of ovipositor (=short) (1).

41. Spermathecal body: subcylindrical (0); subglobose (1); globose (2).

42. Duct-lobe (collum) of spermatheca: conical, very short (0); truncate conical, short (1); tubular (2)

43. Gland-lobe (ramus) of spermatheca: indistinct to slightly developed (0); well-developed (1).

44. Cornu of spermatheca: short (0); medium length to long (1); very long (2).

\section{Male genitalia}

45. Ratio between length of penis apodemes and length of penis body (LAp/Lml): apodemes slightly shorter than penis body, (2\3-3\4) (0); about half as long as penis body (1).

46. Angle between longitudinal axis of penis body and its apodemes: almost flat (0); obtuse to about $90^{\circ}(1)$.

47. Apex of penis, shape in dorsal view: tapering into a long acute projection ( 0$)$; slightly pointed (1); rounded, with a pointed projection at apex (2); evenly rounded (3).

48. Endophallic armature: absent, no distinct sclerotized pieces (0); present, with wing-like sclerotized pieces (1) with long sclerotization like flagelum (2).

49. Apex of penis, curvature in lateral view: not recurved (0); dorsally slightly recurved (1) dorsally strongly recurved (2) 
Table 2 (on next page)

Data matrix of Leschenius plus five outgroups. 


\begin{tabular}{|c|c|c|c|c|c|c|c|c|c|c|c|c|c|c|c|c|c|c|c|c|c|c|c|c|c|c|c|c|c|c|}
\hline & & & & & 0 & & & & & & & & & & & 1 & & & & & & & & & & 2 & & & & \\
\hline & 0 & 1 & 2 & 3 & 4 & 5 & 6 & 7 & 8 & 9 & 0 & 1 & 2 & 3 & 4 & 5 & 6 & 7 & 8 & 9 & 0 & 1 & 2 & 3 & 4 & 5 & 6 & 7 & 8 & 9 \\
\hline Melanocyphus lugubris & 2 & 2 & 0 & 1 & 1 & 0 & 0 & 0 & 1 & 0 & 0 & 1 & 0 & 2 & 0 & 0 & 1 & 3 & 1 & 0 & 1 & 0 & 0 & 0 & 1 & 0 & 1 & 2 & 0 & 2 \\
\hline Trichocyphus formosus & 2 & 1 & 2 & 0 & 0 & 0 & 0 & 0 & 1 & 0 & 0 & 1 & 0 & 0 & 0 & 0 & 1 & 0 & - & 0 & 0 & 0 & - & 0 & 0 & 0 & 0 & 0 & 0 & 2 \\
\hline Amitrus nitens & 2 & 2 & 0 & 1 & {$\left[\begin{array}{ll}1 & 3\end{array}\right]$} & 0 & 1 & 0 & 1 & 0 & 0 & 1 & 1 & 1 & 0 & 0 & 0 & 1 & 0 & 0 & 0 & 0 & 1 & 0 & 0 & 0 & 1 & 1 & 0 & 1 \\
\hline Amphideritus vilis & 1 & 1 & 2 & 3 & 2 & 0 & 1 & 0 & 2 & 1 & 0 & 1 & 1 & 0 & 0 & 0 & 1 & 0 & 0 & 0 & 0 & 0 & 0 & 0 & 0 & 0 & 1 & 0 & 0 & 1 \\
\hline Asymathetes pascoei & 0 & 0 & 1 & 2 & 1 & 1 & 1 & 0 & 0 & 0 & 0 & 1 & 1 & 1 & 0 & 0 & 2 & 1 & 0 & 1 & 2 & 0 & 0 & 0 & 0 & 0 & 0 & 1 & 1 & 1 \\
\hline Leschenius rugicollis & 1 & 2 & 1 & 3 & 2 & 1 & 0 & 1 & 0 & 0 & 1 & 0 & 1 & 1 & 0 & 1 & 0 & 2 & 1 & 1 & 0 & 2 & 1 & 1 & 1 & 1 & 1 & 0 & 1 & 0 \\
\hline Leschenius nigrans & 2 & 2 & 1 & 2 & 1 & 1 & 0 & 1 & 0 & 0 & 1 & 1 & 1 & 0 & 0 & 1 & 1 & 2 & 1 & 0 & 2 & 1 & 1 & 1 & 1 & 2 & 0 & 0 & 1 & 0 \\
\hline Leschenius vulcanorum & 0 & 2 & 1 & 2 & 1 & 2 & 1 & 0 & 0 & 0 & 1 & 1 & 2 & 1 & 1 & 1 & 1 & 2 & 0 & 1 & 0 & 1 & 0 & 1 & 0 & 0 & 1 & 0 & 1 & 0 \\
\hline Leschenius manueli & 1 & 2 & 1 & 3 & 2 & 1 & 0 & 1 & 0 & 1 & 1 & 0 & 1 & 2 & 1 & 1 & 1 & 2 & 0 & 1 & 0 & 2 & 1 & 1 & 1 & 0 & 0 & 0 & 1 & 0 \\
\hline Leschenius bifurcatus & 2 & 2 & 1 & 1 & 1 & 1 & 0 & 1 & 0 & 1 & 1 & 1 & 2 & 2 & 0 & 0 & 0 & 0 & - & 0 & 0 & 1 & 0 & 1 & 1 & 2 & 1 & 0 & 1 & 0 \\
\hline Leschenius silviae & 1 & 2 & 1 & 2 & 1 & 1 & 0 & 1 & 0 & 0 & 1 & 1 & 2 & 0 & 1 & 0 & 1 & 2 & 1 & 1 & 2 & 2 & 1 & 1 & 1 & 0 & 1 & 0 & 1 & 0 \\
\hline Lescheniu ventrilingulatus & 0 & {$\left[\begin{array}{ll}1 & 2\end{array}\right]$} & 1 & 2 & 1 & 2 & 1 & 0 & 0 & 0 & 1 & 1 & 2 & 2 & 1 & 0 & 1 & 2 & 0 & 1 & 0 & 1 & 0 & 1 & 0 & 0 & 1 & 0 & 1 & 0 \\
\hline
\end{tabular}

\begin{tabular}{|c|c|c|c|c|c|c|c|c|c|c|c|c|c|c|c|c|c|c|c|c|}
\hline & & & & & 3 & & & & & & \multicolumn{10}{|c|}{4} \\
\hline & 0 & 1 & 2 & 3 & 4 & 5 & 6 & 7 & 8 & 9 & 0 & 1 & 2 & 3 & 4 & 5 & 6 & 7 & 8 & 9 \\
\hline Melanocyphus lugubris & 3 & 3 & 1 & 0 & 0 & - & 1 & 0 & 1 & 0 & - & 2 & 0 & 1 & 0 & 0 & 0 & 1 & 0 & 0 \\
\hline Trichocyphus formosus & 0 & 0 & 0 & 0 & 1 & - & 1 & 0 & 1 & 1 & 0 & 0 & 0 & 0 & 1 & - & - & - & - & - \\
\hline Amitrus nitens & 1 & 1 & 1 & 0 & {$\left[\begin{array}{ll}0 & 1\end{array}\right]$} & 0 & 1 & 0 & 2 & 1 & 1 & 0 & 1 & 0 & 1 & 0 & 0 & 2 & 1 & 0 \\
\hline Amphideritus vilis & 2 & 0 & 2 & 0 & 3 & 0 & 1 & 1 & 1 & 0 & 0 & 0 & 1 & 0 & 1 & 0 & 0 & 2 & 0 & 0 \\
\hline Asymathetes pascoei & 2 & 1 & 2 & 2 & 1 & 2 & 1 & 1 & 0 & 0 & 0 & 0 & 1 & 0 & 2 & 0 & 0 & 1 & 0 & 0 \\
\hline Leschenius rugicollis & 1 & 1 & 1 & 1 & 3 & 1 & 1 & 0 & 1 & 0 & 0 & 0 & 1 & 0 & 2 & 0 & 0 & 3 & 1 & 0 \\
\hline Leschenius nigrans & 2 & 0 & 0 & 1 & 3 & 3 & 1 & 0 & 1 & 1 & 0 & 0 & 1 & 0 & 2 & 1 & 1 & 1 & 1 & 0 \\
\hline Leschenius vulcanorum & 2 & 1 & 1 & 1 & 2 & 3 & 0 & 0 & 1 & 0 & 0 & 0 & 1 & 0 & 1 & 0 & 0 & 0 & 2 & 1 \\
\hline Leschenius manueli & 2 & 2 & 1 & 1 & 3 & 2 & 1 & 1 & 1 & 1 & 1 & 0 & 1 & 1 & 1 & 0 & 0 & 3 & 2 & 0 \\
\hline Leschenius bifurcatus & 2 & 3 & 1 & 1 & 0 & 1 & 0 & 0 & 1 & 1 & 1 & 0 & 1 & 1 & 2 & 1 & 0 & 1 & 1 & 2 \\
\hline Leschenius silviae & 1 & 2 & 0 & 1 & 2 & 3 & 1 & 0 & 1 & 0 & 0 & 1 & 2 & 0 & 2 & 1 & 1 & 1 & 0 & 0 \\
\hline Leschenius ventrilingulatus & 2 & 1 & 1 & - & 3 & 1 & 1 & 1 & 1 & 1 & 0 & 0 & 1 & 0 & 1 & 0 & 0 & 0 & 2 & 1 \\
\hline
\end{tabular}

